\title{
SISTEM PENDUKUNG KEPUTUSAN PEMBERIAN KREDIT REKENING KORAN PADA BANK JATIM
}

\author{
Christine Kartika Dewi ${ }^{1}$, Faisal Rahutomo ${ }^{2}$ \\ ${ }^{1}$ Program Studi Teknik Informatika, ${ }^{2}$ Jurusan Teknologi Informasi, ${ }^{3}$ Politeknik Negeri Malang \\ ${ }^{1}$ christin.dewy@gmail.com, ${ }^{2}$ faisal.polinema@gmail.com
}

\begin{abstract}
Abstrak
Permintaan kredit melalui bank sudah berkembang sangat pesat. Bank sendiri berperan penting dalam perkembangan perekonomian. Bentuk pelayanan bank sendiri ialah berupa tabungan dan penyalur kredit. Sebagai penyalur kredit bank berperan penting untuk membantu permasalahan keuangan bagi masyarakat. Kelayakan suatu kredit juga dipengaruhi oleh beberapa kriteria tertentu. Sistem Pendukung Keputusan merupakan salah satu solusi yang berfungsi untuk mempermudah pihak bank dalam memberi kredit kepada nasabahnya dengan cara membandingkan data nasabah sehingga dapat meminimalisir kesalahan pihak bank dalam pemberian kredit. Salah satu metode Sistem Pendukung Keputusan adalah metode SAW dengan konsep mendasar untuk mencari penjumlahan tebobot dari rating kinerja pada setiap alternatif pada semua atribut atau kriteria nasabah. Penelitian ini dilakukan dengan mencari nilai bobot untuk setiap atribut, kemudian dilakukan proses perangkingan yang menentukan alternatif yang optimal, yaitu nasabah yang layak mendapatkan kredit.
\end{abstract}

Kata kunci : Sistem Pendukung Keputusan, Kredit, Simple Additive Weight (SAW)

\section{Pendahuluan}

Permintaan kredit melalui bank sudah berkembang sangat pesat. Bank sendiri berperan penting dalam perkembangan perekonomian. Bentuk pelayanan bank sendiri ialah berupa tabungan dan penyalur kredit. Sebagai penyalur kredit bank berperan penting untuk membantu permasalahan keuangan bagi masyarakat.

Di Bank Jatim ini ada berbagai macam kredit beserta kebutuhannya. Dalam pemberian kredit kepada para nasabah harus melalui beberapa tahap terlebih dahulu. Untuk melakukan penilaian masingmasing Sistem Pendukung Keputusan salah satu komponen yang cukup penting dalam sistem informasi yang dibuat sebagai suatu cara untuk memenuhi kebutuhan yang dituju.

Kelayakan suatu kredit juga dipengaruhi oleh beberapa kriteria tertentu, Di Bank Jatim penulis mengambil data tentang kredit rekening koran. Kredit ini merupakan fasilitas pembiayaan untuk membiayai modal kerja yang diberikan kepada nasabah untuk memenuhi modal kerja dan memiliki jangka waktu tertentu. Semakin tingginya minat nasabah untuk mendapatkan kredit dari Bank, membuat pihak Bank masih menyeleksi dalam menentukan siapa yang layak menerima kredit. Dengan adanya sistem pendukung keputusan proses penilaian untuk calon nasabah akan lebih mudah dalam mengakses data dan dapat membandingkan data nasabah sehingga dapat meminimalkan kesalahan dalam pemberian kredit.

Ada beberapa metode dalam membangun Sistem Pendukung Keputusan salah satunya adalah metode SAW dengan konsep mendasar untuk mencari penjumlahan tebobot dari rating kinerja pada setiap alternatif pada semua atribut atau kriteria kreditur. Sistem ini berusaha membantu mengatasi masalah yang terjadi diatas dan sistem ini lebih bersifat memberikan dukungan atau pertimbangan bagi pihak penyeleksi bank dan membantu pihak bank dalam penyeleksi pengambilan keputusan.

Atas dasar permasalahan diatas, agar dapat meningkatkan kelayakan dalam pemberian kredit pada nasabah, maka dibuatlah Sistem Pendukung Keputusan sehingga dapat menjadi alat bantu dalam proses penentuan pemberian kredit untuk nasabah. Yang dimaksudkan untuk menjadi alat bantu yaitu bagi para pengambil keputusan untuk memperluas penilaian mereka tidak untuk menggantikannya. Dengan menggunakan Metode Simple Additive Weighting (SAW) diharapkan dapat membantu dalam proses pemberian kredit.

\section{Tinjauan Pustaka}

\subsection{Sistem Pendukung Keputusan}

Sistem Pendukung Keputusan atau sering disebut Decision Support System (DSS) adalah Sistem berbasis model yang terdiri dari prosedur-prosedur dalam pemrosesan data dan pertimbangannya untuk membantu manajer dalam mengambil keputusan. Agar berhasil mencapai tujuannya maka sistem tersebut harus sederhana, robust, mudah untuk dikontrol, mudah beradaptasi lengkap pada hal-hal penting dan mudah berkomunikasi dengannya. Secara implisit juga berarti bahwa sistem ini harus berbasis komputer dan digunakan sebagai tambahan 
dari kemampuan penyelesaian masalah dari seseorang.

\subsection{Simple Additive Weight (SAW)}

Simple Additive Weight (SAW) adalah salah satu metode dari Multiple Attribute Decision Making (FMADM) yang paling sering digunakan. Konsep dasar metode Simple Additive

Weighting $(S A W)$ adalah mencari penjumlahan terbobot dari rating kinerja pada setiap alternatif pada semua atribut. Metode Simple Additive Weighting $(S A W)$ membutuhkan proses normalisasi matriks keputusan (X) ke suatu skala yang dapat diperbandingkan dengan semua rating alternatif yang ada.

Metode Simple Additive Weighting (SAW) ini mengharuskan pembuat keputusan menentukan bobot bagi setiap atribut. Skor total untuk alternatif diperoleh dengan menjumlahkan seluruh hasil perkalian antara rating (yang dapat dibandingkan lintas atribut) dan bobot tiap atribut. Rating tiap atribut haruslah bebas dimensi dalam arti telah melewati proses normalisasi matriks sebelumnya.

Formula untuk melakukan normalisasi tersebut adalah :

$$
r_{i j}=\left\{\begin{array}{l}
\frac{X_{i j}}{\operatorname{Max}_{i} X_{i j}} \text { Jika } \mathrm{j} \text { atribut keuntungan (benefit) } \\
\frac{\operatorname{Min}_{i} X_{i j}}{X_{i j}} \text { Jika j atribut biaya (cost) }
\end{array}\right.
$$

Keterangan :

$\mathrm{r}$ ij = Rating kinerja ternormalisasi

Maxi = Nilai maksimum dari setiap baris dan kolom

$\mathrm{Xij}=$ Baris dan kolom dari matriks

Mini = Nilai minimum dari setiap baris dan kolom

Nilai preferensi untuk setiap alternatif (Vi) diberikan sebagai :

$$
V_{i}=\sum_{j=i}^{n} W_{i} r_{i j}
$$

Keterangan :

$$
\begin{array}{ll}
\mathrm{V}_{\mathrm{i}} & =\text { Nilai akhir dari alternatif } \\
\mathrm{W}_{\mathrm{i}} & =\text { Bobot yang telah ditentukan } \\
\mathrm{r}_{\mathrm{ij}} & =\text { Normalisasi matriks }
\end{array}
$$

\section{Desain Sisitem}

\subsection{Use Case Diagram}

Use case diagram ialah model fungsional sebuah system yang menggunakan actor dan use case. Use case adalah layanan (services) atau fungsi-fungsi yang disediakan oleh system untuk penggunanya
(Henderi et al, 2008). Use Case adalah suatu pola atau gambaran yang menunjukan prilaku atau kebiasaan system.

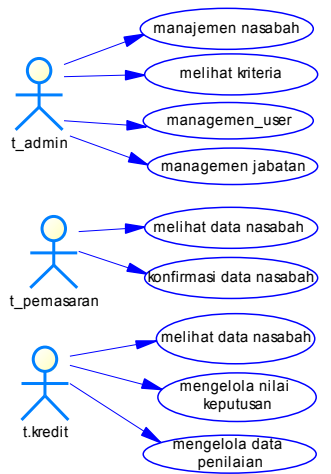

Gambar 3.1: Use Case Diagram

\subsection{Contex Diagram}

DFD (Data Flow Diagram) adalah representasi grafik yang menggambarkan aliran informasi dan transformasi informasi yang diaplikasikan sebagai data yang mengalir dari masukan (input) dan keluaran (output).

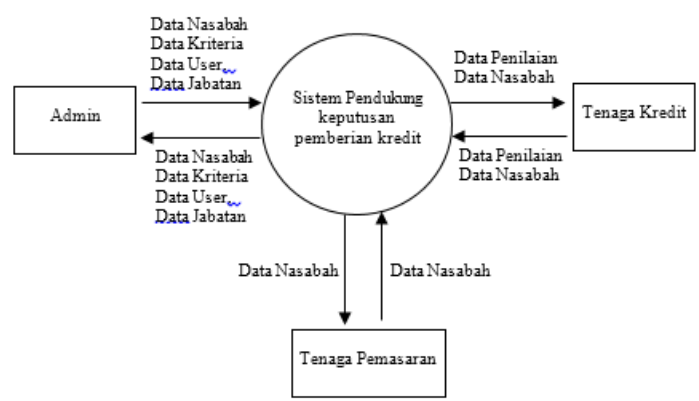

Gambar 3.2: Contex Diagram

Aplikasi yang akan dibangun adalah Sistem Pendukung Keputusan Pemberian Kredit rekening Koran menggunakan metode SAW. User pada sistem ini ada 3, yaitu :

a) Admin

Admin atau administrator akan diberi hak untuk login, dan otoritas untuk memasukkan data nasabah melakukan menejemen view, delete dan read pada data nasabah. Dan melakuakan manajemen edit pada data kriteria dan jabatan. Pada User ini yang bertugas untuk mengelola data nasabah.

b) Tenaga Pemasaran

Tenaga Pemasaran adalah user yang bertugas untuk mengkonfirmasi daftar nasabah siapa saja yang akan di konfirmasi untuk megajukan kredit, dan melakukan login pada sistem 


\section{c) Tenaga Kredit}

Tenaga Kredit adalah akan diberi hak untuk login user ini bertugas untuk mengambil keputusan dalam penentuan pemberian kredit kepada nasabah. Tenaga Kredit melakukan penilaian, melakukan perhitungan SAW untuk menjalankan SPK penentuan pemberian kredit, dan melihat hasil penilaian.

\section{Implementasi}

- Halaman Login

Halaman login adalah halaman awal yang muncul ketika SPK ini diakses, sehingga Admin, Tenaga Pemasaran, Tenaga Kredit harus memasukkan username dan password untuk diautentikasi oleh sistem. Implementasi dari Halaman Login akan ditunjukkan pada Gambar 4.1.

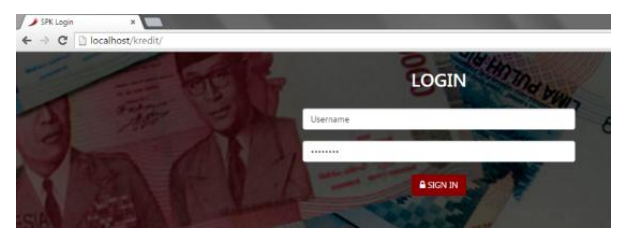

Gambar 4.1 Halaman Login

- Halaman Pengujian Metode SAW

Perhitungan SAW dilakukan ketika bobot sudah ditentukan, dan sudah dilakukan penilaian kepada masing-masing nasabah. Setelah dilakukan perhitungan SAW, sistem akan menghasilkan urutan calon nasabah sesuai dengan hasil nilai yang didapatkan dari perhitungan SAW. Kemudian setelah didapatkan hasil urutan perangkingan calon nasabah.

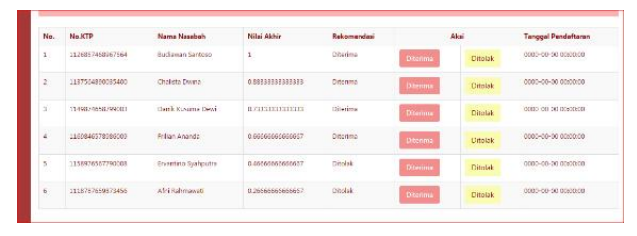

Gambar 4.2 Halaman Pengujian Metode

- Desain database untuk aplikasi Sistem Pendukung Keputusan sebagai berikut:

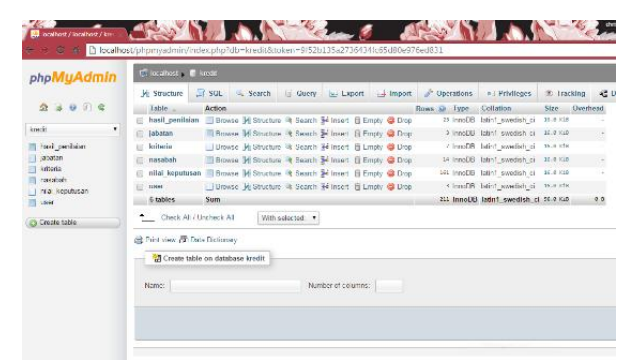

Gambar 4.3 Desain database

\section{Pengujian}

Pengujian sistem pendukung keputusan untuk penentuan pemberian kredit dengan langkah-langkah yang dilakukan adalah proses penetuan bobot tiap kriteria, perhitungan menggunakan metode SAW. Untuk penentuan rekomendasi pemberian kredit rekening koran.

a.) Penentuan Bobot

Bobot ditentukan oleh pihak PT.Bank Jatim Cabang Ngawi Cabang Pembantu Kedunggalar dengan kebijakan yang ada dengan total $100 \%$. Berikut tampilan penentuan bobot pada SPK Pemberian Kredit Rekening Koran. Bobot yang diberikan adalah $(0.25,0.25,0.2,0.2,0.04,0.03$, $0.03)$.

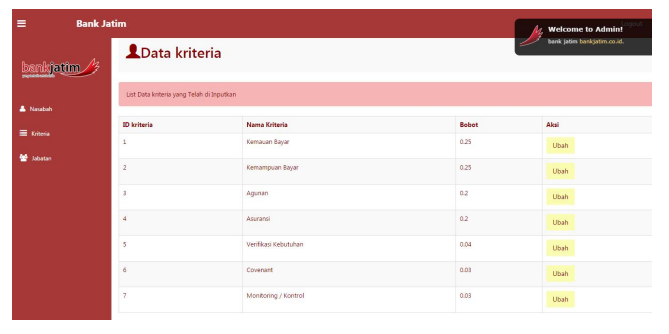

Gambar 5.1 Halaman bobot

b.) Penilaian Nasabah

Untuk Tahap Penilaian Nasabah aktor yang memiliki hak adalah Tenaga Kredit dengan memberikan nilai pada masing-masing calon nasabah dengan 5 penilaian yaitu "Sangat Kurang", "Kurang”, "Cukup", "Baik", "Sangat Baik". Berikut contoh penilaian yang diberikan kepada calon nasabah yang bernama "Chalista Dwina".

Berikut halaman penilaian nasabah, akan ditunjukkan pada gambar 5.2.

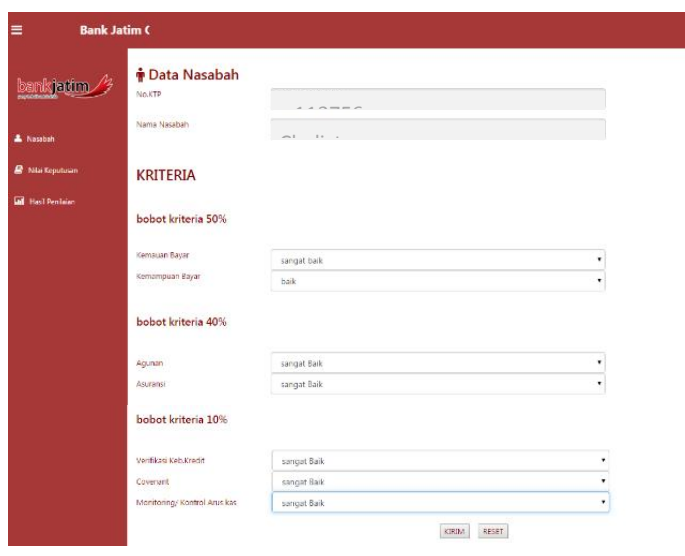

Gambar 5.2 Halaman Penilaian 
c.) Perhitungan SAW

Perhitungan SAW dilakukan ketika bobot sudah ditentukan, dan sudah dilakukan penilaian kepada masing-masing nasabah. Setelah dilakukan perhitungan SAW, sistem akan menghasilkan urutan calon nasabah sesuai dengan hasil nilai yang didapatkan dari perhitungan SAW. Kemudian setelah didapatkan hasil urutan perangkingan calon nasabah.

Berikut tampilan jika perhitungan SAW sudah terhitung akan muncul hasil seperti berikut: nasabah Chalista Dwina memiliki nilai akhir : 0.883333 dengan rekomendasi diterima.

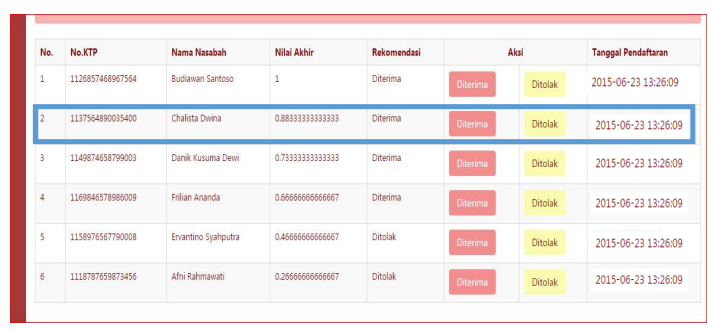

Gambar 5.3 Halaman hasil perhitungan

\section{Pembahasan}

- Pembahasan Hasil

Dari percobaan pengujian di atas didapatkan kesimpulan bahwa tingkat keberhasilan pembuatan sistem ini telah berhasil dilakukan setelah melakukan implementasi pada sistem pendukung keputusan untuk pemberian kredit dengan menerapkan metode SAW yang menghasilkan hasil yang sama dengan hasil perhitungan pengujian manual menggunakan metode SAW. Hal ini dibuktikan dengan mengambil jumlah contoh 6 data calon nasabah, 4 dari 6 data calon nasabah telah menghasilkan hasil keputusan sesuai dengan yang diharapkan. Berikut dibuktikan dalam gambar tabel di bawah ini.

Gambar 6.1 Hasil Pembahasan

\begin{tabular}{|c|c|c|c|c|}
\hline Nama & \begin{tabular}{|c|} 
Hasil \\
Pengujian \\
Manual \\
\end{tabular} & $\begin{array}{c}\text { Hasil Pengujian } \\
\text { SPK }\end{array}$ & Error & $\begin{array}{c}\text { Prosentase } \\
\text { Error }\end{array}$ \\
\hline Afni Rahmawati & 0.266667 & 0.26666666666667 & 0,0000 & $0 \%$ \\
\hline Budiawan Santoso & 1 & 1 & 0,0000 & $0 \%$ \\
\hline Chalista Dwira & 0.883333 & 0.88333333333333 & 0,0000 & $0 \%$ \\
\hline Danik Kusuma Dewi & 0.733333 & 0.73333333333333 & 0,0000 & $0 \%$ \\
\hline Ervantino Syahputra & 0.466667 & 0.46666666666667 & 0,0000 & $0 \%$ \\
\hline Frilian Ananda & 0.666667 & 0.66666666666667 & 0,0000 & $0 \%$ \\
\hline \multicolumn{3}{|r|}{ Rata-Rata Error } & & $0 \%$ \\
\hline
\end{tabular}

Pada tabel di atas telah dilakukan analisa terhadap pengujian yang dilakukan dengan menggunakan metode SAW. Hasil pengujian awal adalah hasil perhitungan yang dilakukan dengan pengujian manual dan hasil pengujian pada implementasi sistem spk. Sedangkan nilai error merupakan selisih dari hasil pengujian manual dengan hasil pengujian spk.

\section{Kesimpulan dan Saran}

\subsection{Kesimpulan}

Berdasarkan penelitian yang dilaksanakan oleh penulis pada sistem pendukung keputusan untuk Pemberian Kredit Rekening Koran dengan metode SAW, dapat ditarik kesimpulan sebagai berikut:

1. Sistem pendukung keputusan pemberian kredit dengan metode SAW telah dibuat dan dapat berjalan dengan baik secara fungsional dan menghasilkan output yang diharapkan.

2. Penerapan metode SAW menghasilkan rekomendasi calon nasabah untuk bagian kredit yang layak mendapatkan penerimaan kredit.

3. Metode SAW dapat menerapkan jenis kriteria dan pembobotan sesuai kriteria kredit rekening Koran. Perhitungan SAW akan menghasilkan suatu peringkat dalam membandingkan hasil nilai tiap calon nasabah sesuai nilai kriteria. Sistem ini telah diuji dengan membandingkan hasil output sistem dengan perbandingan manual berdasarkan hasil tersebut sistem dapat menentukan kelayakan penerimaan kredit.

4. Metode SAW secara efektif dan cepat mampu memberikan alternatif pilihan optimal dalam penentuan kelayakan calon nasabah berdasarkan peringkat dan berdasarkan nilai pembobotan yang diberikan.

\subsection{Saran}

Adapun saran untuk menigkatkan kinerja dan penyempurnaan sistem pendukung keputusan yang telah dibuat:

1. Sistem pendukung keputusan pemberian kredit rekening koran ini perlu dilengkapi dengan metode-metode lainnya, sehingga dapat dilakukan perbandingan hasil dari metode SAW dengan metode lainnya.

2. Sistem yang dibangun diharapkan dapat dijadikan bahan dalam pengembangan dan penelitian lebih lanjut sehingga mampu menghasilkan sistem pendukung keputusan yang tidak hanya terbatas untuk rekening Koran.

\section{Daftar Pustaka:}

Afshari, A., M. Mojahed and R.M. Yusuff, 2010. Simple additive weighting approach to personnel selection problem. Int. J. Innov. Manage., Technol., 1: 511- 515. DOI: 10.7763/IJIMT.2010.V1.89

Akhmad, 2006, Aplikasi Exel dalam Pengambilan Keputusan Memilih Kredit, Penerbit Elex Media Komputindo, Jakarta. 
A. Toloie Eshlaghy et al, Sensitivity analysis for criteria values in decision making matrix of saw metod. International Journal of Industrial Mathematics, 1, 69-75, 2009.

Hariyani, I.,Toruan, R.L.2010.Restrukturisasi dan Penghapusan Kredit Macet.Elex Medi Komputindo.

Kusrini, M.Kom. (2007). Konsep dan Aplikasi Sistem Pendukung Keputusan. Yogyakarta : Andi.

Kusumadewi, Sri;Hartati, Sri;Harjoko, Agusdan Wardoyo, Retantyo.2006.Fuzzy.

Nugroho, Bunafit 2004, Aplikasi Pemograman Web Dinamis dengan PHP dan MySQ, Gava Media,Yogyakarta
Nursyamsiah, Diyah.2013. Analisis dan Perancangan Sistem Pendukung Keputusan Untuk Penentuan Jalur Kelompok Keahlian Menggunakan Model Simple Additive Weighting (SAW) . Konferensi Nasional Sistem Informasi 2013 (KNSI-373). Universitas Pasunda.

Product Knowledge Bank Jatim, 2013.

Turban, Efraim.2005.Decision Support Systems and Intelligent Systems, edisi Bahasa Indonesia jilid 1.Penerbit Andi.Yogyakarta.

Wahab, R.A.2010.Sistem Pendukung Keputusan Pemberian Pinjaman Kredit Menggunakan The Satisficing Model. Universitas Komputer Indonesia 